\title{
An Experimental Approach to the Measurement of Wall Pressure Generated by an Underwater Spark-Generated Bubble by a Hopkinson Bar
}

\author{
Xiongliang Yao $\mathbb{D}$, Xiongwei Cui $\mathbb{B}$, Kai Guo, and Yingyu Chen $\mathbb{D}$ \\ College of Shipbuilding Engineering, Harbin Engineering University, Harbin 150001, China \\ Correspondence should be addressed to Xiongwei Cui; cuixiongwei@yahoo.com
}

Received 17 November 2018; Revised 7 March 2019; Accepted 5 May 2019; Published 27 May 2019

Academic Editor: Chengzhi Shi

Copyright (c) 2019 Xiongliang Yao et al. This is an open access article distributed under the Creative Commons Attribution License, which permits unrestricted use, distribution, and reproduction in any medium, provided the original work is properly cited.

\begin{abstract}
The wall pressure loading due to the underwater spark-generated bubble, having served as an efficient technique to study the underwater explosion, has drawn much attention. Compared with the numerical study of the pressure characteristics, the direct experimental investigation is much rarer. Recently, an improved pressure-measuring system by using a Hopkinson pressure bar as the sensing element is proposed, set up, and validated by the current authors. In this article, the improved methodology and experimental system is used to detect and analyze the pressure loading on the target plate surface due to the underwater spark-generated bubble beneath the plate. A series of experiments with $3 \mathrm{~mm}, 5 \mathrm{~mm}, 10 \mathrm{~mm}, 15 \mathrm{~mm}, \ldots, 60 \mathrm{~mm}$ standoffs are carried out. The experimental results and the related analysis and discussions are presented. Based on the results, the improved methodology can be used to detect the pressure loading due to the spark-generated bubble. There is multipeak oscillation near the peak of the shock pressure loading profile. The peak pressure versus the standoff is also summarized. According to the characteristics of the induced water jet pressure and the bubble-collapse pressure loading given in this article, enough attention should be paid to not only the jet and the first bubble-collapse pressure loadings but also the secondary bubble-collapse pressure loadings especially when the dimensionless distance $\gamma>1$.
\end{abstract}

\section{Introduction}

The underwater spark-generated bubble has served as an important and efficient technique to study underwater explosion and cavitation bubbles due to its low cost and other advantages. Cui et al. use the spark-generated bubble to study the ice plate's dynamics and breaking under the attack of underwater bubble collapse [1], opening another interesting field. The interaction between the underwater spark-generated bubble and the ice plate is given and investigated, as well as the mechanism how the ice plate is damaged by the collapsing bubble. Taylor et al. proposed a new method to generate pressure waves by using the nonequilibrium microsecond pulsed spark [2]. Goh et al. studied the spark-generated bubble near an elastic sphere [3], in which the affection of the elasticity, the dimensionless standoff, the size ratio of the bubble, and the elastic sphere perimeter on the interaction between the bubble and the elastic sphere is discussed. Li et al. studied the interaction between the spark-generated bubble and a suspended rigid sphere [4]. When the underwater bubble collapses, a shock wave is generated. Ishii and Watanabe proposed an excellent experimental apparatus to study this type of shock wave pressure [5]. The dynamics of underwater bubble near different boundaries draws much attention, such as the large-scale bubble close to different boundaries by Zhang et al. [6], between a free surface and a rigid wall by Zhang et al. [7], and near a two-layered composite beam by Gong et al. [8]. The spark-generated bubble also serves as a validating technique to validate the proposed numerical methods used to simulate the underwater bubble, such as the boundary element [9]. 
Compared with the underwater bubble in a free field, the underwater bubble near a solid plate surface is more complex and interesting. Due to the overexpansion, the pressure in the surrounding water is higher than that inside the bubble, resulting in the bubble shrinking rapidly. In the procedure of shrinking, a water jet is induced under the help of Bjerknes effect, the inertia and the gravity [4]. After travelling through the whole bubble, the water jet impacts on the target plate surface, leaving a water jet pressure loading on the surface [10-12]. As mentioned above, a bubblecollapse pressure loading is released and acts on the target then [1]. So the pressure loading on the target surface subjected to an underwater bubble is a combination of the shock wave pressure, the water jet pressure, and the bubblecollapse loadings. The characteristics of the pressure loading due to the bubble collapse have drawn much attention. Li et al. gave a detailed analysis of the pressure field on the target surface above which the bubble is formed through the boundary element method validated by the spark-generated bubble [13]. The induced bubble pressure is analyzed deeply by dividing the whole pressure into two parts, which are discussed separately. Li et al. studied the pressure loading due to the induced water jet through numerical methods $[9,14]$, as well as Liu et al. [15] and Zhang et al. [16]. Through experiments and numerical simulations, the process and mechanism of the induced water jet are given in detail. Wang et al. proposed a combining level set-modified ghost fluiddiscontinuous Galerkin method, which is validated by the spark-generated bubble, to study and analyze the pressure characteristics due to the bubble collapse in compressible fluid [17]. It should be pointed out that the study and analysis mentioned above regarding the bubble-collapse and water jet pressure loading are investigated through numerical methods, which is validated by experimental results. For the experimental study, Krieger and Chahine give the acoustic signals' characteristics of the underwater sparkgenerated bubble near different boundaries by using a PCB 102A03 piezoelectric transducer [18]. From the acoustic signals, accurate predictions of the bubble pulse, depths, etc., can be made. A series of experiments with different standoffs were carried out by Jayaprakash et al. [19] to investigate the pressure loading, assessed by a PCB $101 \mathrm{~A} 03$ pressure transducer, on the vertical wall subjected to the spark-generated bubble. Based on the experimental results, the two peaks of the pressure signals are analyzed and discussed. Recently, Luo et al. studied the pressure loading on the target plate surface above which a low-voltage spark-generated bubble is formed [20]. They give a detailed analysis and discussion of the pressure due to the secondary bubble collapse. So from the work conducted by other researchers, direct experimental measurement and study of the pressure loading generated by the underwater sparkgenerated bubble is much rarer due to the extremely violent electric discharge in the generation of the bubble. In the case of small standoffs, the electric discharge may lay a heavy damage to the traditional pressure transducer.

Recently, a new experimental system has been developed and manufactured to assess the wall pressure loading generated by a near-field underwater explosion [21] and the high-voltage underwater spark-generated bubble [22] by current the authors. In the experimental measurement system, the Hopkinson pressure bar $[23,24]$, serving as the sensing element, is inserted through the hole drilled on the target plate. And the end face of the bar lies flush with the loaded face of the target plate. Through the strain gauges tapped on the Hopkinson pressure bar, the strain in the bar can be detected, based on which the pressure loading acting on the target plate surface can be obtained. This methodology has been used by many other researchers to detect different types of pressure loadings, such as the pressure loading of the buried explosions [25-29], the pressure loading of the blasts in air [30], and the pressure loading due to the high-speed sand column impact [31]. As pointed out by the current authors previously [21], some improvements should be made before this methodology can be used to detect the pressure loading due to the near-field underwater explosions consisting more than one phase pressure loadings. Firstly, all the key elements of the system are enclosed in the waterproof enclosure. Secondly, the bar is pulled firmly against the hard rubber cylinder at the distal end of the bar by a pair of ropes to ensure the end face of the bar flush with the target plate surface during the whole duration of the underwater explosion. The current authors also proposed and established a validating method: underwater explosions between two parallel plates to validate the improved methodology. In the validating experimental system, the explosive is fixed at the middle point between the two parallel plates. The Hopkinson bar-based measurement system is used to assess the pressure on the center point of the upper plate, and a traditional pressure transducer is used to get the pressure of the lower plate. By comparing the pressure profiles gotten by the Hopkinson bar-based measurement system and the pressure transducer, the proposed measurement system is validated. It is recommended to refer to the details given in reference [21].

Here, the improved methodology proposed by the current authors is used to assess the pressure loading due to the spark-generated bubble to testify the improved methodology's capability further and investigate the pressure loading experimentally. Compared with the high-voltage underwater spark-generated bubble experiments [22], the low-voltage underwater spark-generated bubble experiment has been widely investigated by researchers such as Han et al. [32] and Ma et al. [33]. However, the pressure loading is scarcely got and studied by experiments. So the work conducted in this article aims at assessing the pressure loading on the target plate subjected to the low-voltage underwater spark-generated bubble experimentally and giving a discussion and analysis of the pressure loading with the growth of the standoff, which can serve as validating data for other studies. A series of spark-generated bubble beneath the target plate experiments are carried out in a water tank. The spark-generated bubble is produced by a discharge of $400 \mathrm{~V} \cdot 400 \mu \mathrm{F}$. A National Instruments (NI) PCIe-6376 data acquisition unit (DAU) is used to record the strain signals. The DAU is set to its maximum sample rate $3.57 \mathrm{M}$ samples per second in all the experiments conducted in this article. To validate the proposed methodology and investigate the 
relation between the pressure loading and the bubble dynamics, a high-speed video camera is used to capture the bubble's motions. The camera and DAU are triggered synchronously. The experimental results are presented and studied in detail. According to the results, the improved methodology and the manufactured experimental system are successfully used to detect the pressure loading due the spark-generated bubble. And some characteristics of the pressure loading, especially when the standoff is more than the maximum radius of the bubble in the free field, are given, which means that enough attention should be paid to not only the first bubble-collapse pressure loading but also the secondary bubble-collapse pressure loading.

The rest of this article is arranged as follows. In Section 2, the experimental apparatus and the system, as well as the test plan, are give briefly. The results of the experiments and the discussions are presented in Section 3. In Section 4, some concluding remarks and recommendations for the future work are presented.

\section{Experimental Work}

In this section, the test apparatus and the test system are demonstrated briefly. To get more details about the apparatus and system, it is recommended to refer to our previous work [21]. Especially, the underwater spark generator circuit we used is given, as well as the test plane.

2.1. Apparatus and Test System. A strong aluminium alloy frame serves as the test platform, as shown in Figure 1. The dimension of the water tank is $600 \mathrm{~mm} \times 600 \mathrm{~mm} \times 600 \mathrm{~mm}$. The reinforced glass of the water tank is of high transparency, and the glass thickness is $12 \mathrm{~mm}$. The perfect transparency contributes to capturing the spark-generated bubble motions. To supply strong enough light required by the HSV camera, a halogen light is adopted. The HSV Phantom VEO640S can take 24000 frames per second at a resolution of $512 \times 512$.

A pair of copper tubes, connected to the spark generator, are lapped together. The external and inner diameter of the copper tube are $0.7 \mathrm{~mm}$ and $0.3 \mathrm{~mm}$, respectively. When the spark generator applies the high voltage on the copper tubes, the underwater spark-generated bubble is formed at the lapped point. The circuit of the spark generator is given in Figure 2. The circuit is divided into two separate subareas: the low-voltage control subarea and the high-voltage discharge subarea. The operator can only touch and operate the low-voltage control subarea which controls the high-voltage discharge subarea through relays and contacts. To ensure the operators' safety, the voltage of the low-voltage control subarea is limited to $24 \mathrm{~V}$. In our spark generator, the discharge voltage is $400 \mathrm{~V}$, and the energy is stored in a $400 \mu \mathrm{F}$ capacitor. The safety switch can only be turned to the "On" position by a special key. From the circuit, only when both the safety switch and the ignition switch are closed can the energy stored in the capacitor be discharged to form the underwater bubble, which ensures the operator safety further. Besides, after a bubble forming procedure, there is still

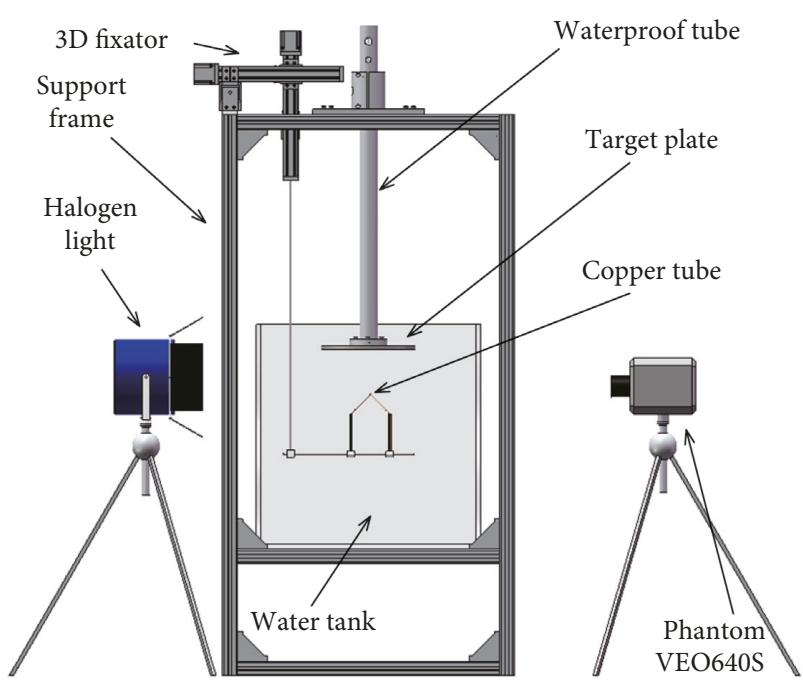

Figure 1: Schematic of the test system.

some energy stored in the capacitor, which leaves hidden dangers for the operators. A discharge resistor is used to consume the remaining energy. The discharge voltage also serves as the trigger signal which is used to trigger the DAU and the HSV synchronously. The copper tubes are positioned by a 3D fixator to the required position, as shown in Figure 1 .

A $12 \mathrm{~mm}$ thick, $250 \mathrm{~mm}$ diameter stainless steel target plate is mounted on the end of the waterproof tube, as shown in Figure 3. Between the target plate and the tube, some seal rings are used to ensure the waterproof. Because the underwater spark-generated bubble is very small, the pressure loading on the target bar is very small. To get a higher strain, an aluminium alloy bar with a diameter of $5 \mathrm{~mm}$ is chosen as the Hopkinson pressure bar. Besides, semiconductor strain gauges mounted on the Hopkinson pressure bar in pairs are adopted to get a higher signal-to-noise ratio. To remove the bending wave disturbance, a wheatstone-bridge circuit is adopted so that the axial strain component can only be detected. The Hopkinson pressure bar is inserted through a hole which is drilled into the target plate. The loaded face of the Hopkinson pressure bar lies flush with the target plateloaded face. On the Hopkinson pressure bar, a pair of ropes are taped to pull the Hopkinson pressure bar firmly against a hard rubber cylinder to guarantee that the loaded face of the Hopkinson pressure bar flush with the target plate-loaded face. The hard rubber cylinder is fixed in a tube which is mounted to the waterproof tube. In the experiments, the bar is chosen to be $2.3 \mathrm{~m}$ long. The strain gauges are placed $0.04 \mathrm{~m}$ from the loaded face of the target plate. According to the shock wave speed obtained by Cui et al. [21], there will be about $0.9124 \mathrm{~ms}$ before the arrival of the reflected wave signal from the distal end.

2.2. Test Plane. In all the experiments, the water in the water tank is $525 \mathrm{~mm}$ deep and the distance between the loaded face of the target plate and the bottom of the water tank is $423 \mathrm{~mm}$, as shown in Figure 4. The maximum radius of the 


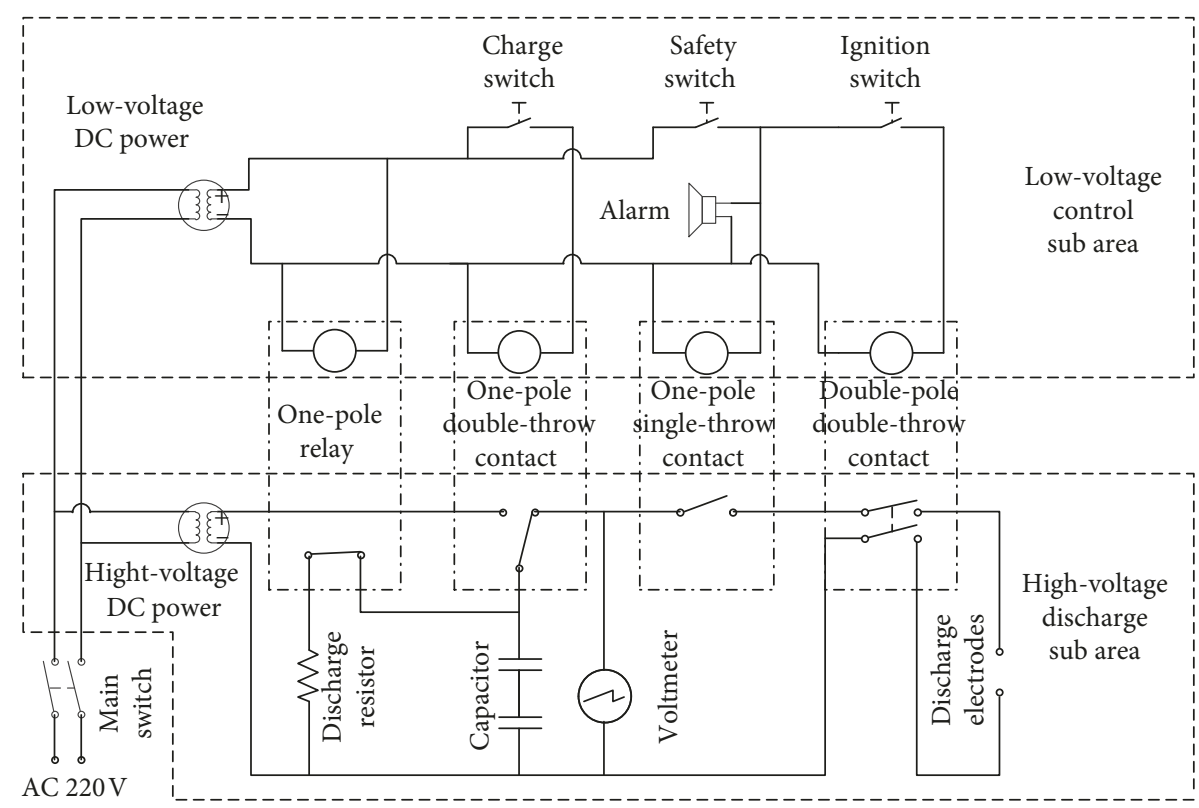

FIgURE 2: The spark-generator circuit.

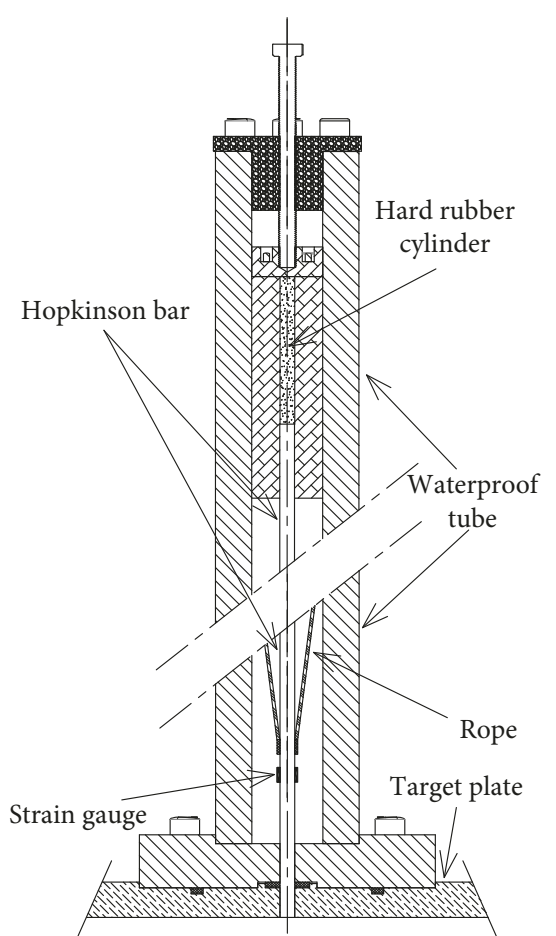

Figure 3: Detailed schematic of the apparatus.

underwater spark-generated bubble is $R_{\mathrm{M}}=30 \mathrm{~mm}$ under the free-field conditions, which are given in the next section. The standoff distance of the experiments is chosen as $3 \mathrm{~mm}$ and $5,10,15, \ldots, 60 \mathrm{~mm}$, which means the dimensionless distance (the ration between the standoff distance and the maximum radius of the underwater spark-generated bubble) $\gamma=0.1$ and $0.167,0.333,0.500, \ldots, 2.000$.

Besides, the experiment that the underwater sparkedgenerated bubble under the free-field conditions is also

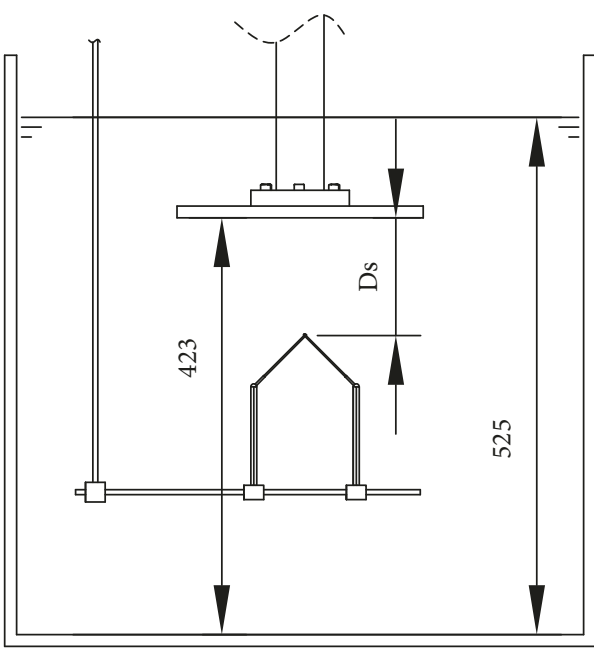

Figure 4: Experimental setup.

carried out. All the experiments carried out in this paper are summarized in Table 1.

\section{Results and Discussion}

3.1. Spark-Generated Bubble in the Free Field. To get the underwater bubble dynamics, especially the maximum radius of the underwater bubble, a spark-generated bubble in the free field is carried out first. The depth of the water is $525 \mathrm{~mm}$, and the lapped point of the two copper tubes is located at a depth of 365 from the bottom of the water tank. The first cycle of the spark-generated bubble's expansion and collapse is shown in Figure 5. About $71.4 \mu$ s after the spark generator applies the discharge voltage, the underwater bubble forms and expands quickly then. The bubble expands to its maximum volume at $t=3.0714 \mathrm{~ms}$, as shown in Figure 5(d). According to Figure 5(d), the maximum radius 
TABle 1: Test planes.

\begin{tabular}{|c|c|c|c|}
\hline Tests & Boundary condition & Standoff & Dimensionless distance $\gamma$ \\
\hline 1 & Free field & - & - \\
\hline 2 & Below the target plate & $3 \mathrm{~mm}$ & 0.100 \\
\hline 3 & Below the target plate & $5 \mathrm{~mm}$ & 0.167 \\
\hline 4 & Below the target plate & $10 \mathrm{~mm}$ & 0.333 \\
\hline 5 & Below the target plate & $15 \mathrm{~mm}$ & 0.500 \\
\hline 6 & Below the target plate & $20 \mathrm{~mm}$ & 0.667 \\
\hline 7 & Below the target plate & $25 \mathrm{~mm}$ & 0.833 \\
\hline 8 & Below the target plate & $30 \mathrm{~mm}$ & 1.000 \\
\hline 9 & Below the target plate & $35 \mathrm{~mm}$ & 1.167 \\
\hline 10 & Below the target plate & $40 \mathrm{~mm}$ & 1.333 \\
\hline 11 & Below the target plate & $45 \mathrm{~mm}$ & 1.500 \\
\hline 12 & Below the target plate & $50 \mathrm{~mm}$ & 1.667 \\
\hline 13 & Below the target plate & $55 \mathrm{~mm}$ & 1.833 \\
\hline 14 & Below the target plate & $60 \mathrm{~mm}$ & 2.000 \\
\hline
\end{tabular}

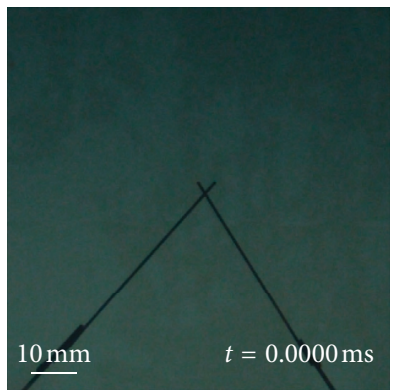

(a)

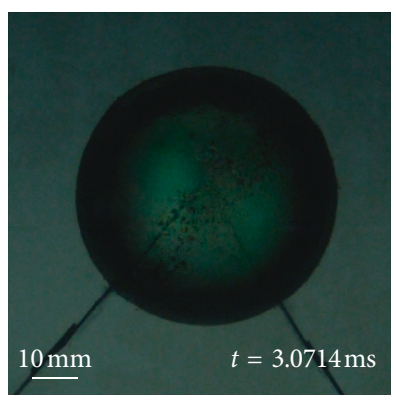

(d)

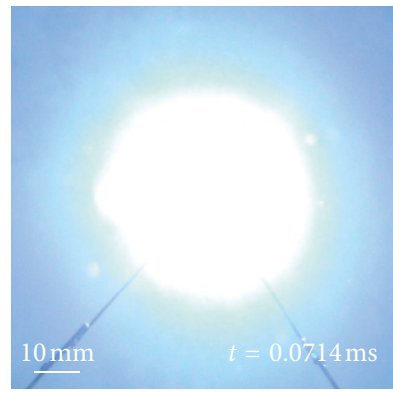

(b)

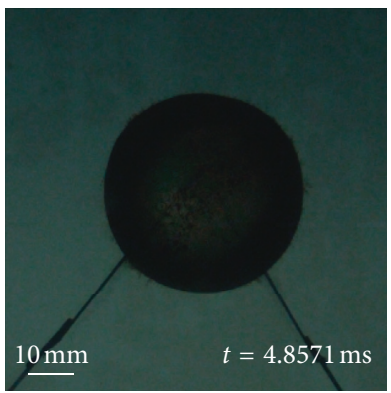

(e)

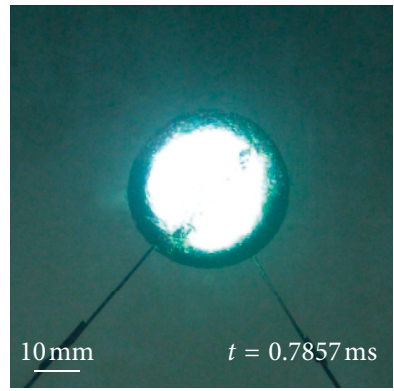

(c)

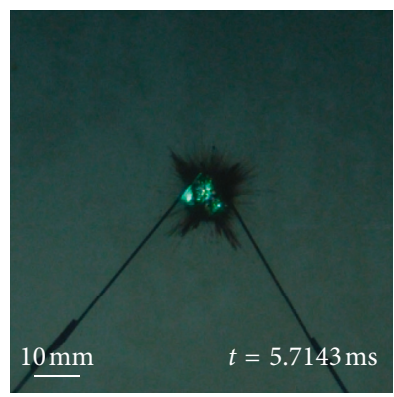

(f)

Figure 5: Evolution of the first cycle of the spark-generated bubble's expansion and collapse in a free field. (a) $t=0.0000 \mathrm{~ms}$. (b) $t=0.0714 \mathrm{~ms}$. (c) $t=0.07857 \mathrm{~ms}$. (d) $t=3.0714 \mathrm{~ms}$. (e) $t=4.8571 \mathrm{~ms}$. (f) $t=5.7143 \mathrm{~ms}$.

of the bubble is about $30 \mathrm{~mm}$ by pixels. The first collapse of the bubble occurs at $t=5.7143 \mathrm{~ms}$, meaning the first bubble period is about $5.6429 \mathrm{~ms}$.

3.2. Experiment Results with $20 \mathrm{~mm}$ Standoff. Firstly, the experiment spark-generated bubble below the target plate at Ds $=20 \mathrm{~mm}$ is taken as the example to present and elaborate the dynamics of the bubble beneath the target plate and the characteristics of the wall pressure loading. The evolution of the first cycle of the underwater bubble's expansion and collapse is shown in Figure 6. The HSV camera captures the images at a rate of $24000 \mathrm{fps}$, meaning that the interval between every image is $41.67 \mu \mathrm{s}$. The pressure profile obtained by the Hopkinson pressure bar is shown in Figure 7.
From the images of the underwater bubble, the bubble expands quickly after the energy is discharged. At $t=4.1945 \mathrm{~ms}$, the bubble expands to its maximum volume after which the bubble enters the collapse sequence. During the collapse procedure, a water jet forms inside the bubble, as shown in Figure 6(e). At $t=7.1112 \mathrm{~ms}$, the bubble collapses. As a result, the pressure loading on the target plate consists of the shock wave, the water jet, and the bubble-collapse pressure loadings. At $t=0.0000 \mathrm{~ms}$, the spark generator applies the voltage on the copper tubes, which will leave a noise on the strain signal, as shown in Figure 7. From the pressure profile shown in Figure 7, the Hopkinson pressure bar detects three separated pressure loadings.

The details of the shock pressure loading are shown in Figure 8(a). Before the bubble forms, there is high-pressure 


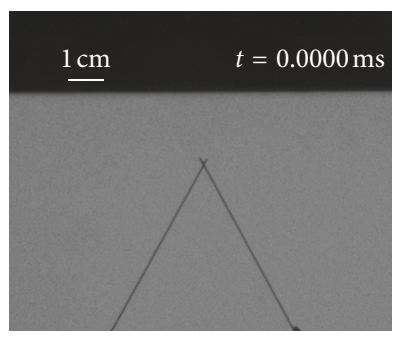

(a)

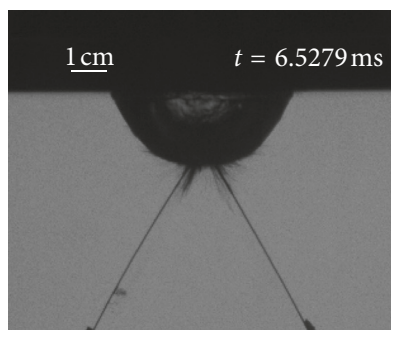

(e)

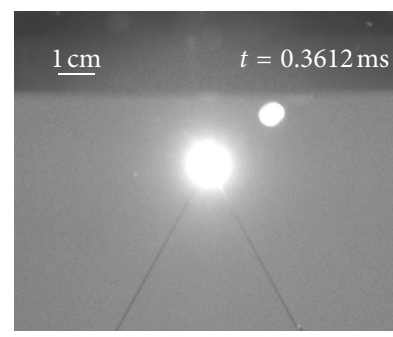

(b)

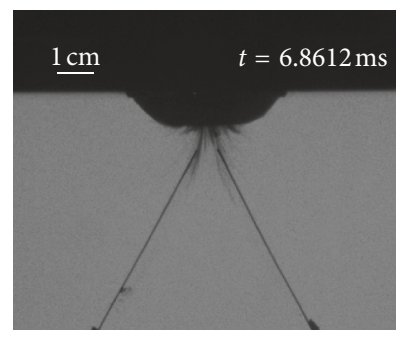

(f)

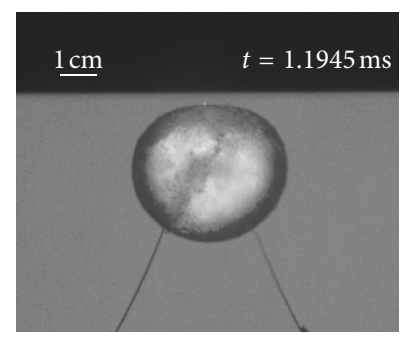

(c)

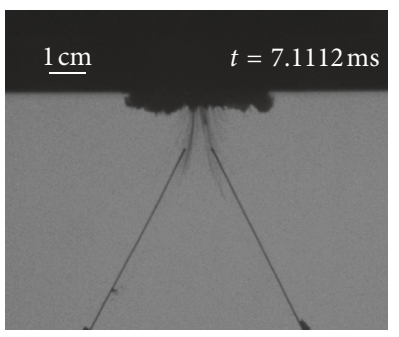

(g)

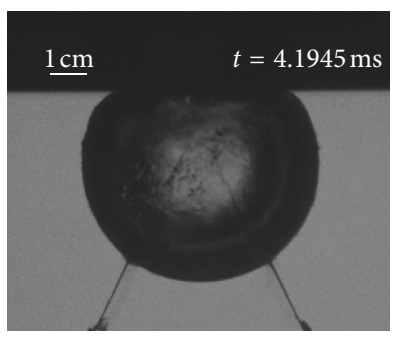

(d)

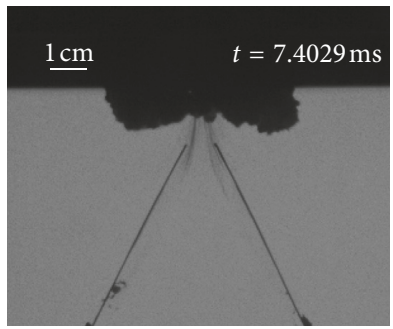

(h)

FIGURE 6: Evolution of the first cycle of the underwater spark-generated bubble's expansion and collapse below the target plate with 20 mm standoff. (a) $t=0.0000 \mathrm{~ms}$. (b) $t=0.3621 \mathrm{~ms}$. (c) $t=1.1945 \mathrm{~ms}$. (d) $t=4.1945 \mathrm{~ms}$. (e) $t=6.5279 \mathrm{~ms}$. (f) $t=6.8612 \mathrm{~ms}$. (g) $t=7.1112 \mathrm{~ms}$. (h) $t=7.4029 \mathrm{~ms}$.

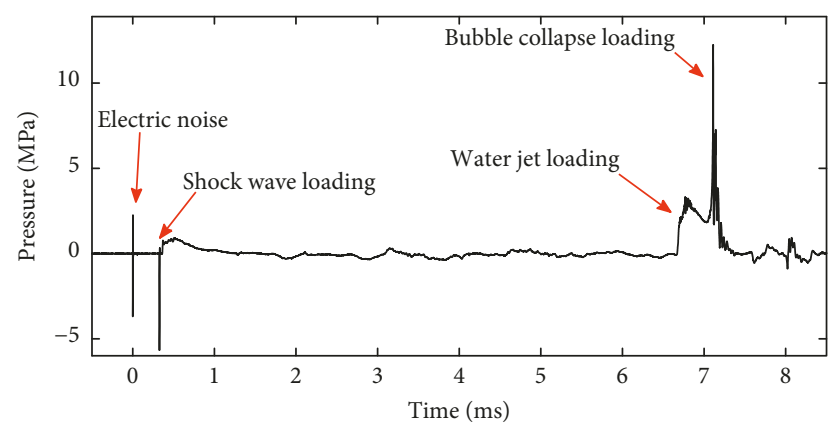

Figure 7: Pressure-time profile recorded by HPB with a $20 \mathrm{~mm}$ standoff.

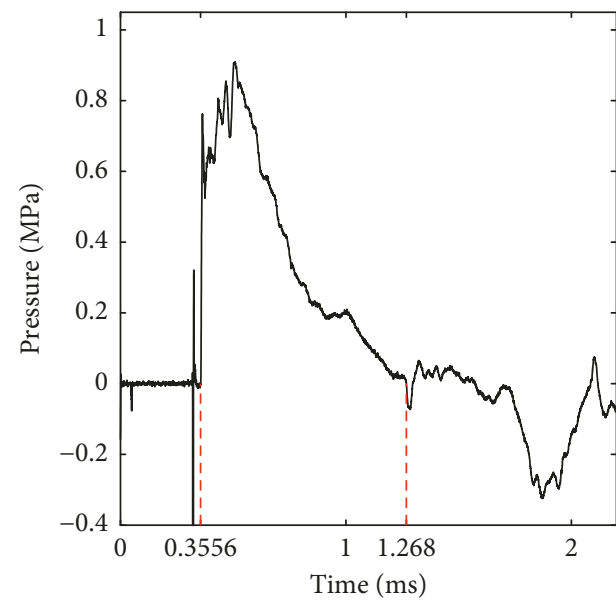

(a)

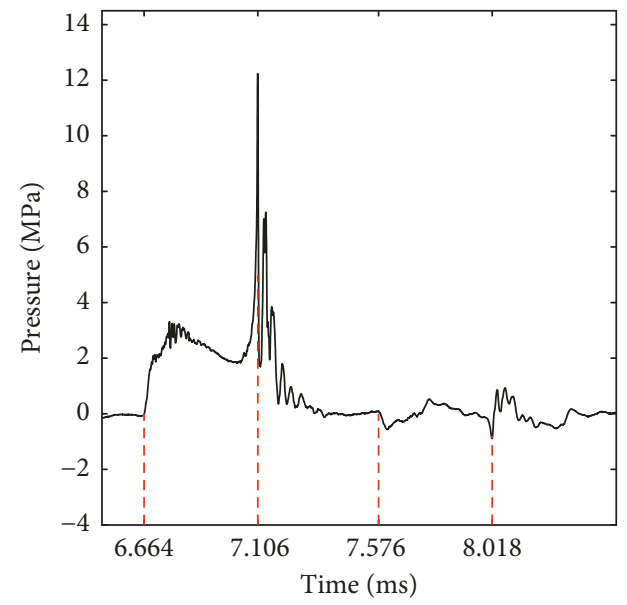

(b)

FIGURE 8: Details of the $20 \mathrm{~mm}$ standoff pressure-time profile. (a) Shock wave pressure loading. (b) Water jet and bubble collapse loading. 
plasma at the lapped point [6]. This will also leave another noise on the strain signal. From the images of the bubble, there is an extremely bright light in the image at $t=0.3612 \mathrm{~ms}$, which means the bubble forms between this image and the previous image, i.e., between $t=319.5 \mu$ s and $t=361.2 \mu \mathrm{s}$. Immediately after the bubble forms, a shock wave is released into the water. According to the acoustic wave velocity in the water, it takes about $13.3 \mu$ s for the shock wave to arrive at the loaded face of the Hopkinson pressure bar, which means the shock wave will arrive at the loaded face between $t=332.8 \mu \mathrm{s}$ and $t=374.5 \mu \mathrm{s}$. From the detailed pressure profile, it is evident that the shock wave begins at $t=355.6 \mu \mathrm{s}$, which coincides with what we deduct from the bubble images. After $0.9124 \mathrm{~ms}$, i.e., $t=1.268 \mathrm{~ms}$, the reflected signal of the shock wave loading is detected. From the pressure profile, it can be found that the pressure loading increases rapidly when the energy is discharged. Unlike the shock wave pressure loading generated by explosive, the shock wave pressure profile does not get its peak directly. There is some oscillation in the profile near the peak. Based on the coincidence between the shock wave pressure profile and the bubble's images and the time interval between the shock wave pressure loading signal and the reflected signal, the shock wave pressure loading can be detected by the Hopkinson pressure bar successfully. It must be pointed out that the detected signal of the HPB consists of the signal of the pressure loading and the reflected signals. To get the pressure history on the target, the reflected signals should be removed properly. As mentioned above, the HPB is long enough that the first reflected signal does not go into the original signal. So to get the pressure profile on the loaded face, the signal which appears more than $0.9124 \mathrm{~ms}$ later than the time when the original signal begins should be remove or set to zero. However, we do not perform the removal of the reflected signals because the reflected signals are essential to explain and present the propagation of the stress wave in the HPB.

In the collapse procedure, a water jet will be induced and travel through the whole bubble, impacting the target plate. In Figure 9, the procedure of water jet impacting the target plate is shown in detail. The red arrow in the images shows the head of the water jet. At $t=6.6529 \mathrm{~ms}$, the water jet gets near the target plate and impacts on the target plate before $t=6.6945 \mathrm{~ms}$, which means the water jet pressure loading begins between $t=6.6529 \mathrm{~ms}$ and $t=6.6945 \mathrm{~ms}$. From the detailed water jet and bubble-collapse loading pressure profile shown in Figure 8(b), the pressure signal detected by the Hopkinson pressure bar beginning at $t=6.664 \mathrm{~ms}$, coinciding with the deduction based on the bubble images. The water jet does not stop impacting until the bubble collapses. The volume of the bubble shown in the $t=7.1112 \mathrm{~ms}$ image is the minimum, which means the bubble collapses between the previous image and the later image, i.e., between $t=7.0650 \mathrm{~ms}$ and $t=7.1574 \mathrm{~ms}$. From the detailed pressure profile, the collapse pressure loading is detected around $t=7.106 \mathrm{~ms}$. It should be pointed out that after impacting the target, the water will travel back into the bubble. As a result, the bubble will split into several subbubbles. When these sub-bubbles collapse, several separate collapse pressure loadings will act on the target plate. So a multipeak pressure signal is detected as shown in Figure 8(b). Also, at $t=(6.664+0.9124) \mathrm{ms}=7.576 \mathrm{~ms}$ and $t=(7.106+0.9124) \mathrm{ms}=8.018 \mathrm{~ms}$, the reflected signals are detected.

The time that these pressure loading signals appear coincides with the occurrence time deducted based on the bubble images and the reflected signals occur at the expected time. From these results and the related discussion given above, the Hopkinson pressure bar can detect pressure loading signals due to the underwater spark-generated bubble. Next, other experiments with different standoff distances will be carried out to investigate our experiment system further. Besides, for further investigation and studies, the experimental data in this article can be obtained from the corresponding author.

3.3. Experiment Results with 3-60 mm Standoff. In Figure 10, the bubble's motion of the experiment with a $3 \mathrm{~mm}$ standoff is shown. In the expanding procedure, the bubble appears as a semisphere, as well as in the shrinking procedure. From the images, no water jet is formed, so there is no water jet pressure loading, which can be confirmed in the pressure profile shown in Figure 11. When the bubble collapses, a high collapse loading acts on the target plate. According to the pressure profile detected by the Hopkinson pressure bar, the collapse loading reaches a peak of $39.13 \mathrm{MPa}$. The bubble-collapse loading has an extremely short duration. As a result, several reflected wave signals are detected perfectly.

With the standoff increasing from $3 \mathrm{~mm}$ to $20 \mathrm{~mm}$, the water jet is induced. When the bubble collapses, there is also a bubble-collapse pressure loading. So there is a combination of water jet pressure and collapse pressure loadings, as shown in Figure 12 for experiments with $10 \mathrm{~mm}, 15 \mathrm{~mm}$, and $20 \mathrm{~mm}$ standoff distances. The pressure peak for the water jet pressure appears in the beginning of the water jet pressure. As the standoff increases, the water jet pressure peak increases from 1.738 MPa for $10 \mathrm{~mm}$ standoff to $4.231 \mathrm{MPa}$ for $30 \mathrm{~mm}$ standoff. However, the bubble-collapse pressure peak decreases with the standoff increasing to $25 \mathrm{~mm}$. When the standoff becomes to $25 \mathrm{~mm}$ and $30 \mathrm{~mm}$, some interesting thing occurs.

From the pressure profiles shown in Figures 12(e) and 12(f), the duration of the water jet pressure loading becomes shorter. And for the bubble-collapse loading, the peaks also become lower. Especially, for the experiment with a $25 \mathrm{~mm}$ standoff, the bubble-collapse loading's duration becomes very long as compared with that of the other experiments' collapse loading. From the bubble images shown in Figure 13, the water jet impacts on the target plate and the bubble appears as a so-called "mushroom" [34]. Also, the width of the water jet is increasing in the shrink procedure as shown in the Figures 13(c) and 13(d). After impacting the target plate, the water jet moves outside along the plate surface, forming the "sideways" jet. Due to the "sideways" jet and the incoming flow around the bubble, the bubble is divided [35], leading to the bubble collapse becoming relatively gentle. As a result, the peak of the bubble-collapse 


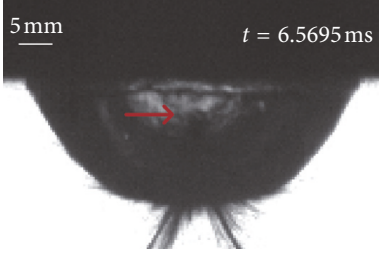

(a)

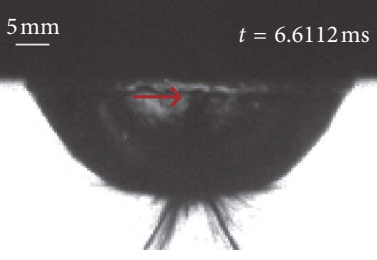

(b)

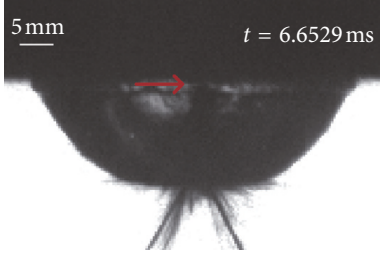

(c)

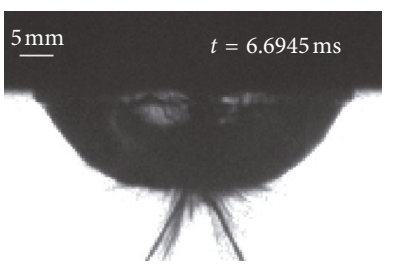

(d)

Figure 9: The procedure of the induced water jet impacting on the target plate with $20 \mathrm{~mm}$ standoff. (a) $t=6.5695 \mathrm{~ms}$. (b) $t=6.6112 \mathrm{~ms}$. (c) $t=6.6529 \mathrm{~ms}$. (d) $t=6.6945 \mathrm{~ms}$.

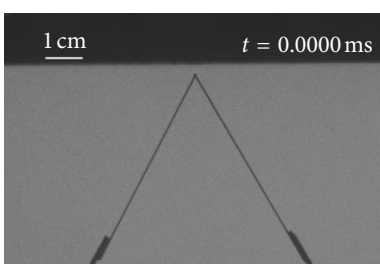

(a)

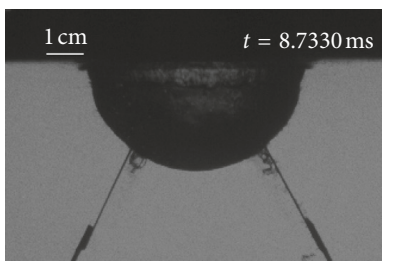

(e)

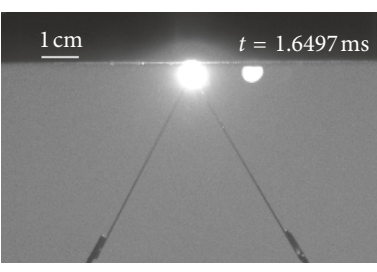

(b)

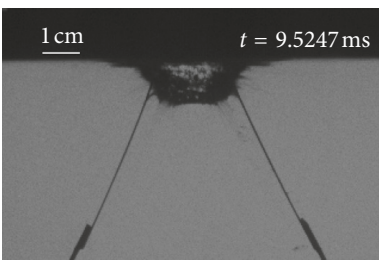

(f)

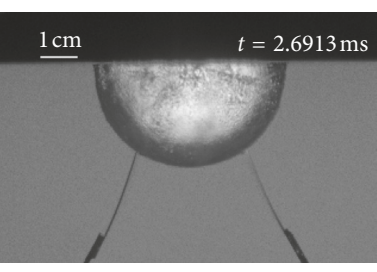

(c)

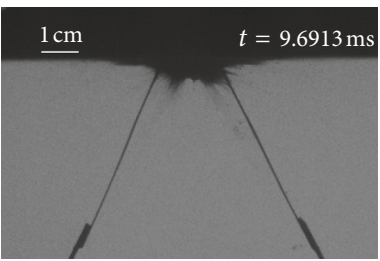

(g)

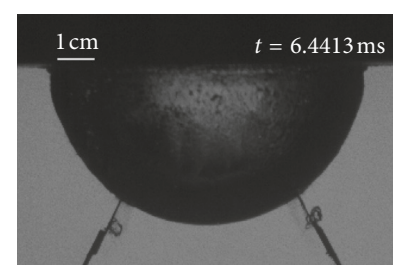

(d)

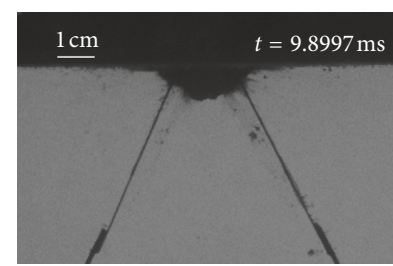

(h)

FIGURE 10: Evolution of the first cycle of the underwater spark-generated bubble's expansion and collapse below the target plate with 3 mm standoff. (a) $t=0.0000 \mathrm{~ms}$. (b) $t=1.6497 \mathrm{~ms}$. (c) $t=2.6913 \mathrm{~ms}$. (d) $t=6.4413 \mathrm{~ms}$. (e) $t=8.7330 \mathrm{~ms}$. (f) $t=9.5247 \mathrm{~ms}$. (g) $t=9.6913 \mathrm{~ms}$. (h) $t=9.8997 \mathrm{~ms}$.

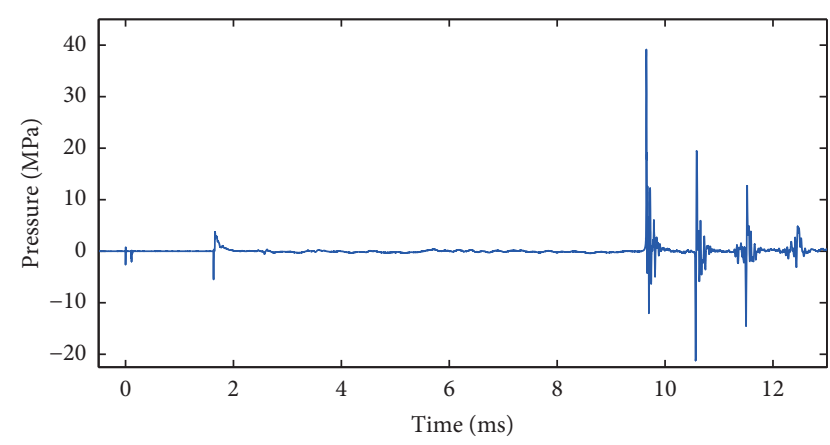

Figure 11: Pressure-time profile recorded by HPB with a $3 \mathrm{~mm}$ standoff.

pressure becomes lower and the duration gets longer. The bubble-collapse pressure profile appears smoother. After the bubble collapses for the first time, the bubble rebounds and expands again, as well as gathers under the plate surface. Then, this bubble begins its shrink procedure. The bubble gets in contact with the plate surface, resulting in that a very high bubble-collapse pressure acts on the target plate when the bubble collapses again. From the pressure profile shown in Figure 12(e), the peak pressure due to the bubble's secondary collapse is higher than that due to the first collapse.
As the standoff increases further, there is still a gap between the bubble and the target plate surface when the bubble collapses. In the bubble's shrink procedure, a water jet is induced, and this water jet travels through the bubble. But it does not impact the target plate surface, as shown in Figure 14. After the first collapse, the bubble moves upward under the influence of buoyancy, inertia, and the Bjerknes effect and gathers under the target plate surface. The bubble begins its secondary expanding-shrinking procedure. When the bubble collapses secondly, another bubble-collapse pressure loading acts on the target plate, as shown in Figure 15. It can be found that the secondary bubble-collapse loading has a much higher peak than the first bubble-collapse loading for the case of $55 \mathrm{~mm}$ and $60 \mathrm{~mm}$ standoffs, which means that we should not only take the first bubble-collapse loading but also pay enough attention to the secondary bubble-collapse loading. Especially, for structures of brittle materials, such as ice, the structures can survive after the first bubble-collapse loading for the loading does not have an enough high peak. But the structures may be damaged under the attack of the secondary bubble-collapse loading because of its high peak.

For the shock wave pressure loading, the pressure rises up rapidly immediately after the energy stored is discharged. Before the pressure gets its peak, there are multipeak curves, 


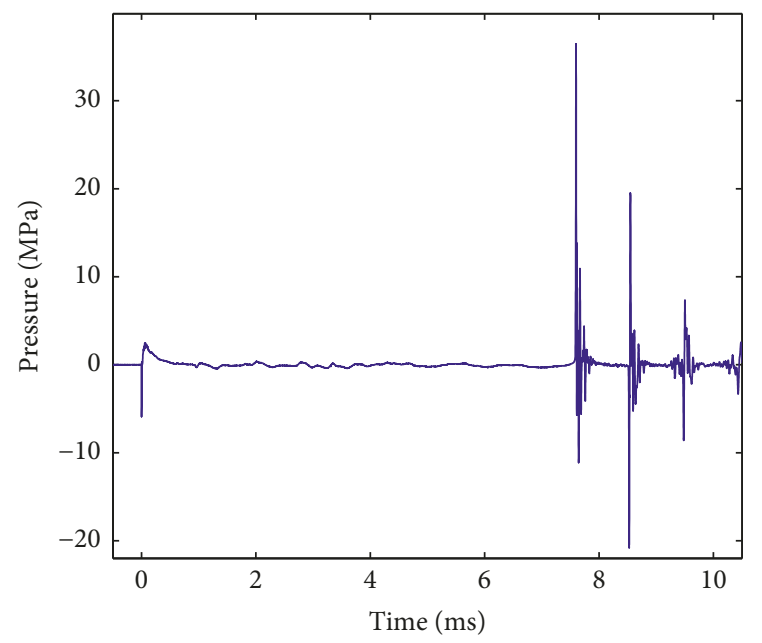

(a)

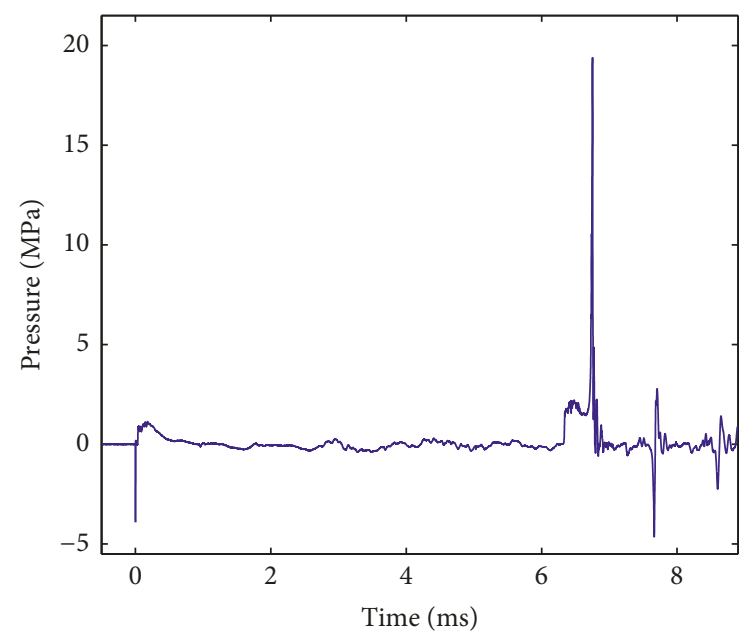

(c)

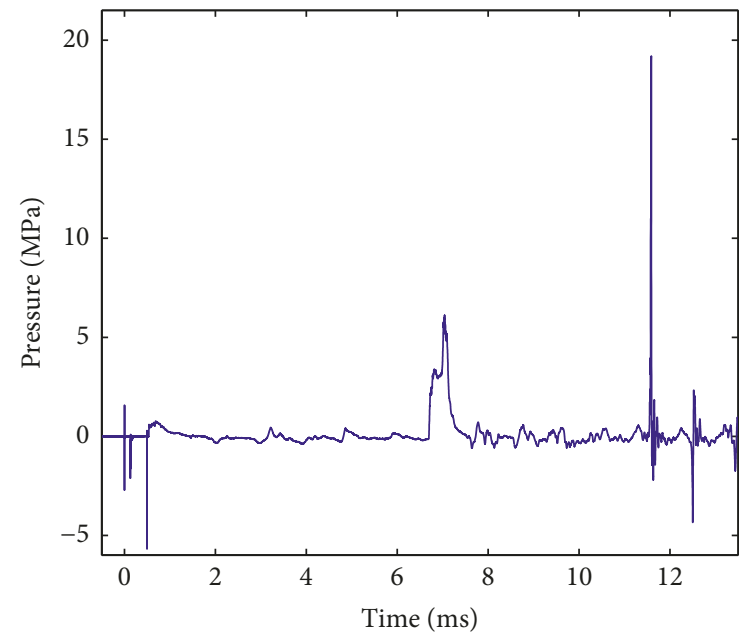

(e)

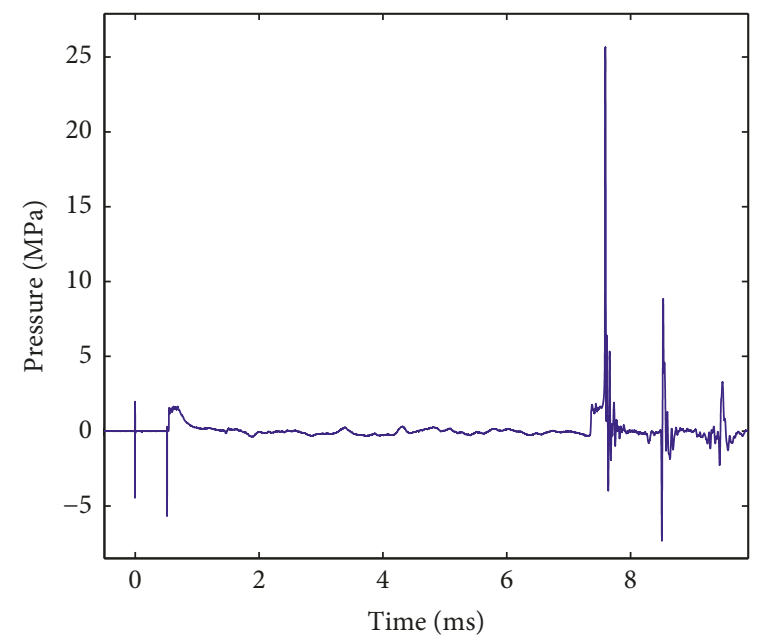

(b)

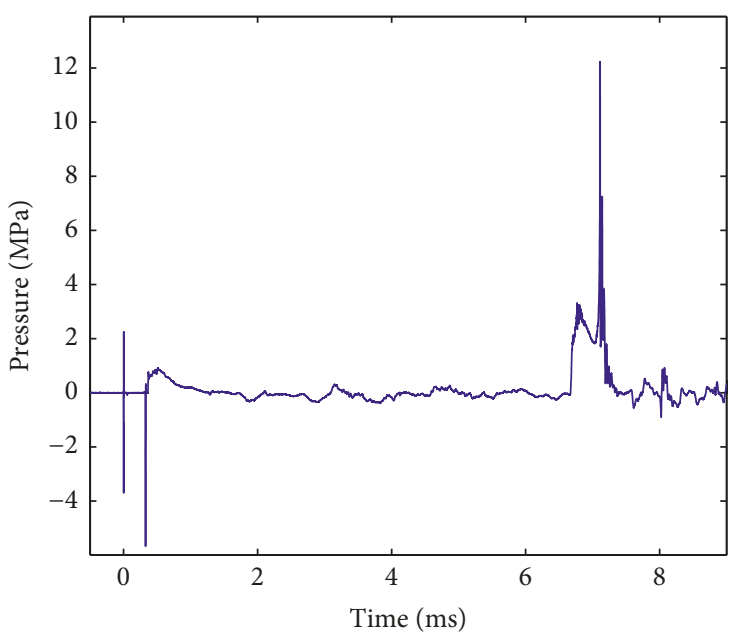

(d)

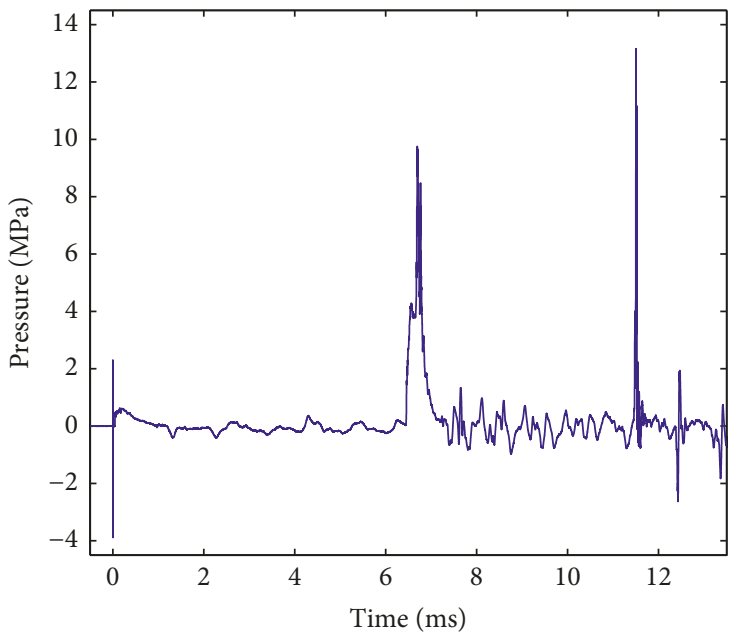

(f)

Figure 12: Pressure-time profile recorded by HPB with a $5 \mathrm{~mm}, 10 \mathrm{~mm}, 15 \mathrm{~mm}, \ldots$, and $30 \mathrm{~mm}$ standoff. (a) $5 \mathrm{~mm}$ standoff. (b) $10 \mathrm{~mm}$ standoff. (c) $15 \mathrm{~mm}$ standoff. (d) $20 \mathrm{~mm}$ standoff. (e) $25 \mathrm{~mm}$ standoff. (f) $30 \mathrm{~mm}$ standoff.

as shown and discussed previously. In Figure 16, the shock pressure loading's peak versus standoff curve is shown. It can be found that the peak pressure loading decreases as the standoff increases. The decreasing fitting equation is as follows: Peak $=4.582 e^{-0.1355 S_{\mathrm{d}}}+0.4754$ with $R_{\text {square }}=0.9782$. 


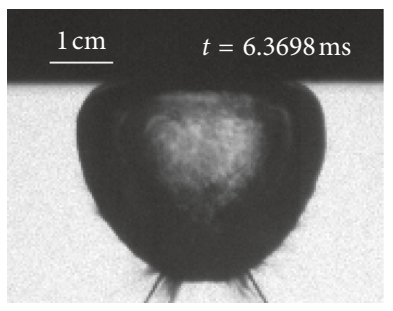

(a)

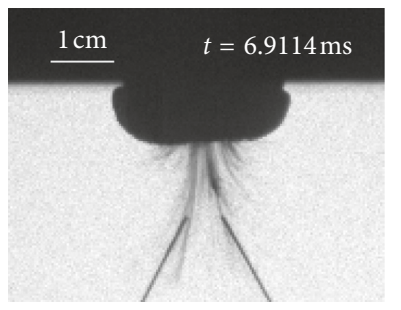

(e)

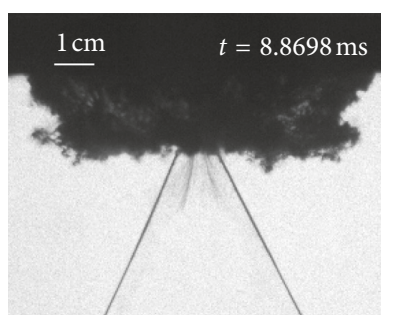

(i)

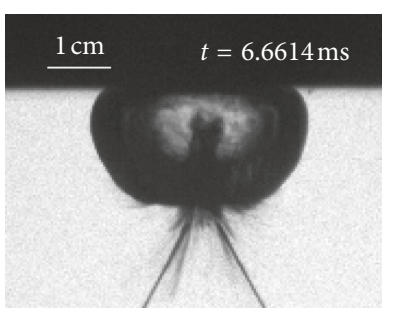

(b)

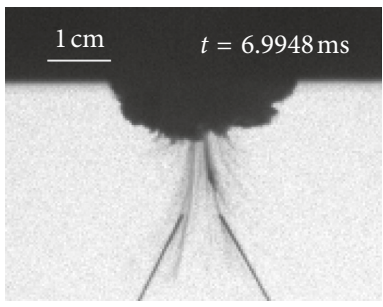

(f)

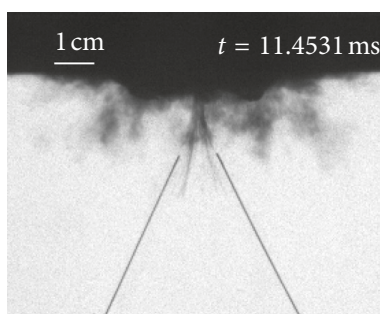

(j)

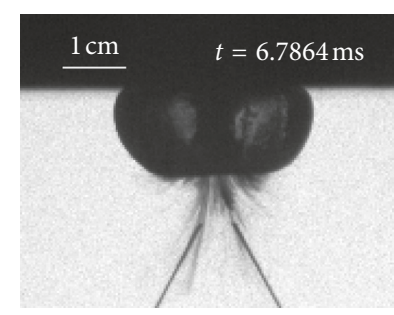

(c)

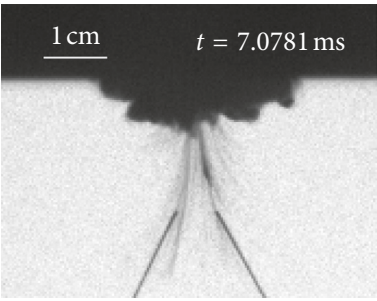

(g)

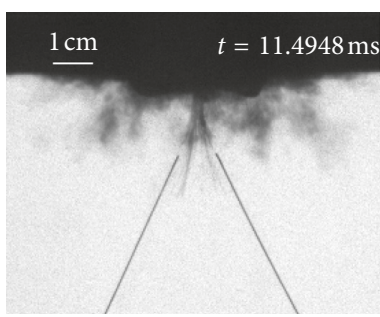

(k)

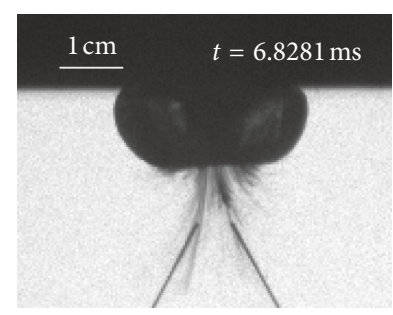

(d)

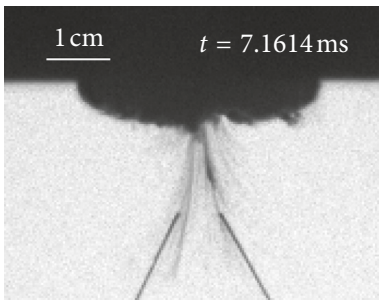

(h)

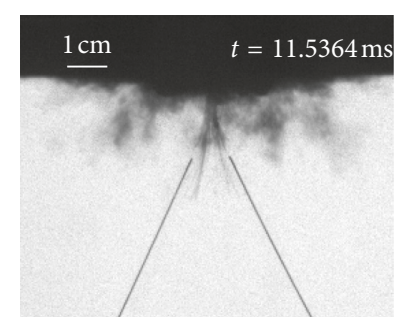

(1)

FIGURE 13: Evolution of the first cycle of the underwater spark-generated bubble's expansion and collapse below the target plate with $25 \mathrm{~mm}$ standoff. (a) $t=6.3698 \mathrm{~ms}$. (b) $t=6.6614 \mathrm{~ms}$. (c) $t=6.7864 \mathrm{~ms}$. (d) $t=6.8281 \mathrm{~ms}$. (e) $t=6.9114 \mathrm{~ms}$. (f) $t=6.9948 \mathrm{~ms}$. (g) $t=7.0781 \mathrm{~ms}$. (h) $t=7.1614$ ms. (i) $t=8.8698 \mathrm{~ms}$. (j) $t=11.4531 \mathrm{~ms}$. (k) $t=11.4948 \mathrm{~ms}$. (l) $t=11.5364 \mathrm{~ms}$.

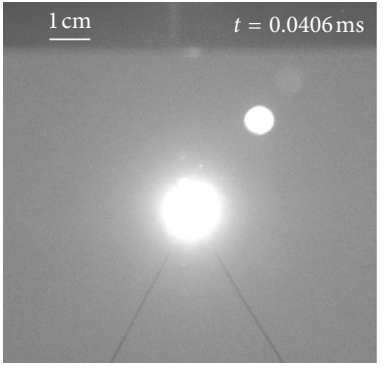

(a)

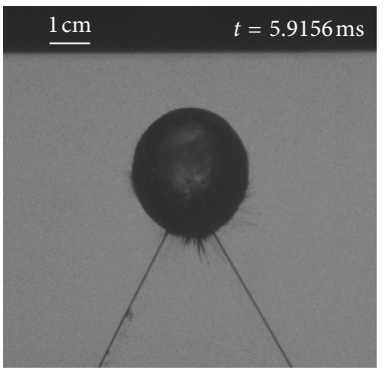

(e)

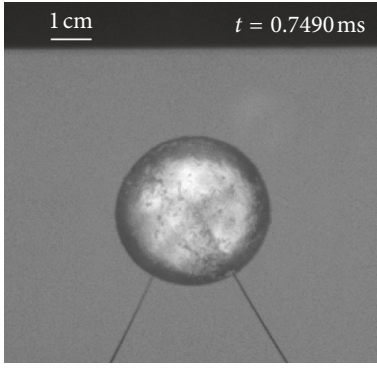

(b)

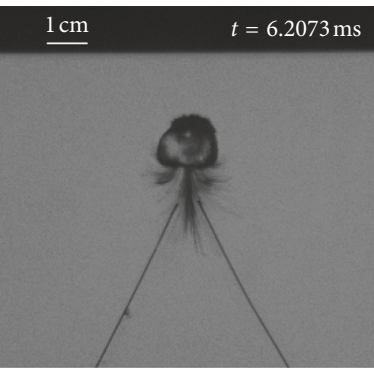

(f)

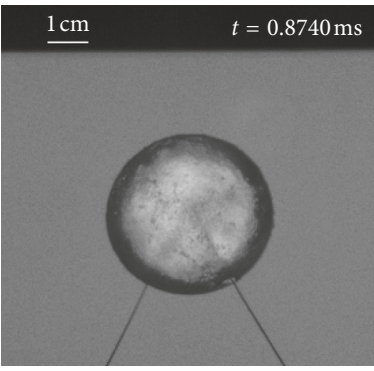

(c)

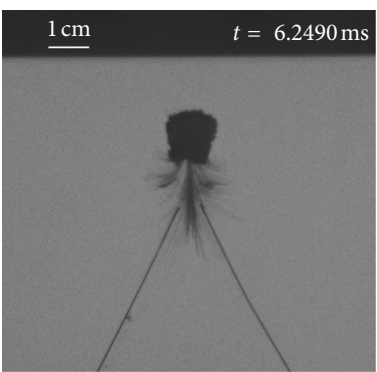

(g)

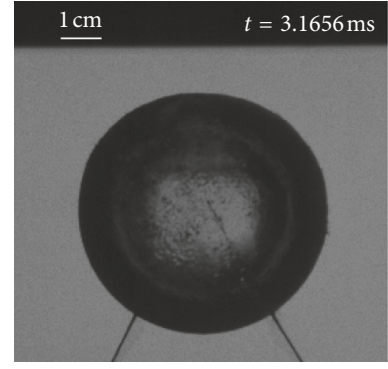

(d)

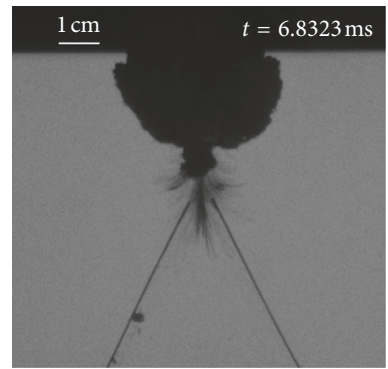

(h)

Figure 14: Continued. 


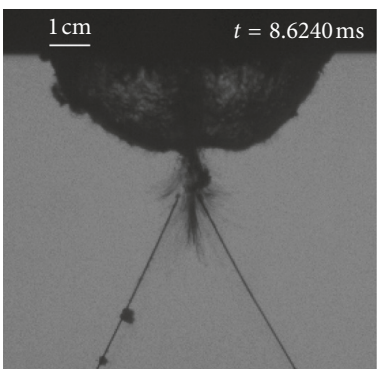

(i)

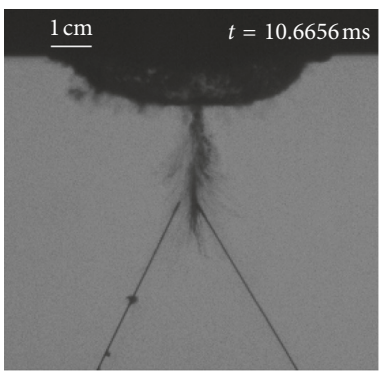

(j)

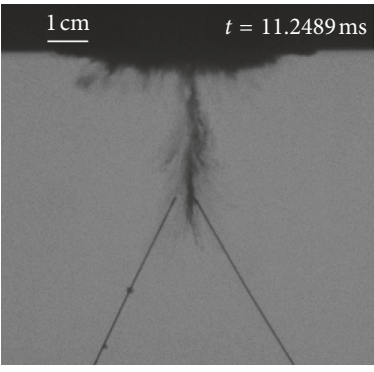

$(\mathrm{k})$

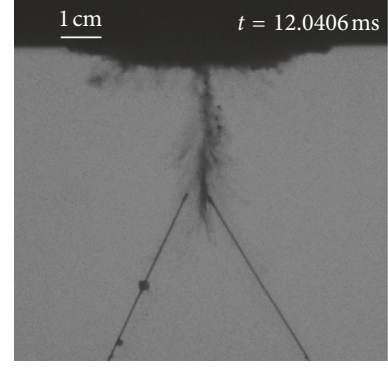

(1)

FIGURE 14: Evolution of the first cycle of the underwater spark-generated bubble's expansion and collapse below the target plate with 40 mm standoff. (a) $t=0.0406 \mathrm{~ms}$. (b) $t=0.7490 \mathrm{~ms}$. (c) $t=0.8740 \mathrm{~ms}$. (d) $t=3.1656 \mathrm{~ms}$. (e) $t=5.9156 \mathrm{~ms}$. (f) $t=6.2073 \mathrm{~ms}$. (g) $t=6.2490 \mathrm{~ms}$. (h) $t=6.8323 \mathrm{~ms}$. (i) $t=8.6240 \mathrm{~ms}$. (j) $t=10.6656 \mathrm{~ms}$. (k) $t=11.2489 \mathrm{~ms}$. (l) $t=12.0406 \mathrm{~ms}$.

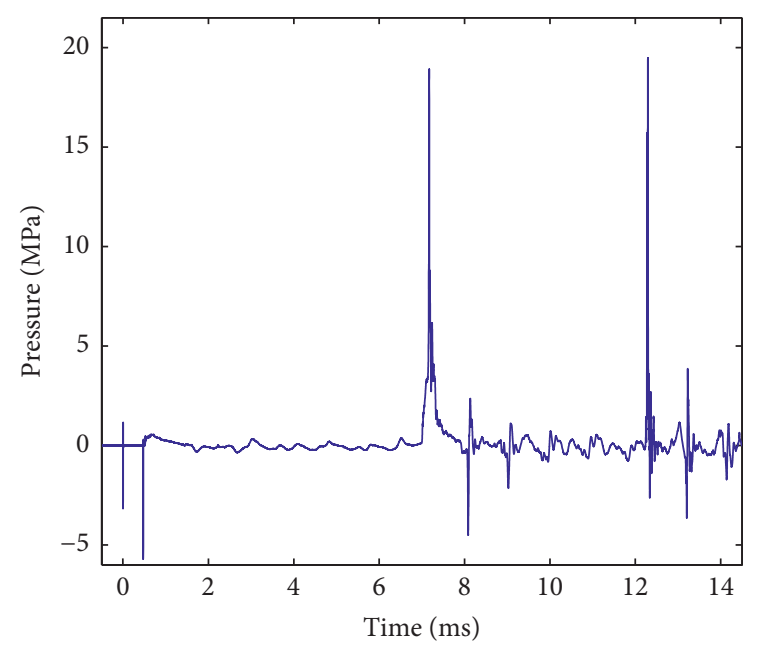

(a)

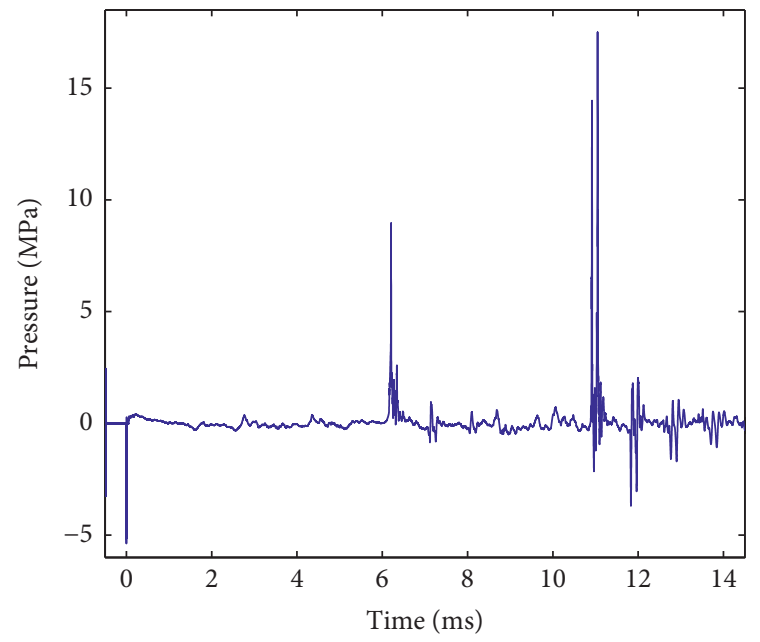

(c)

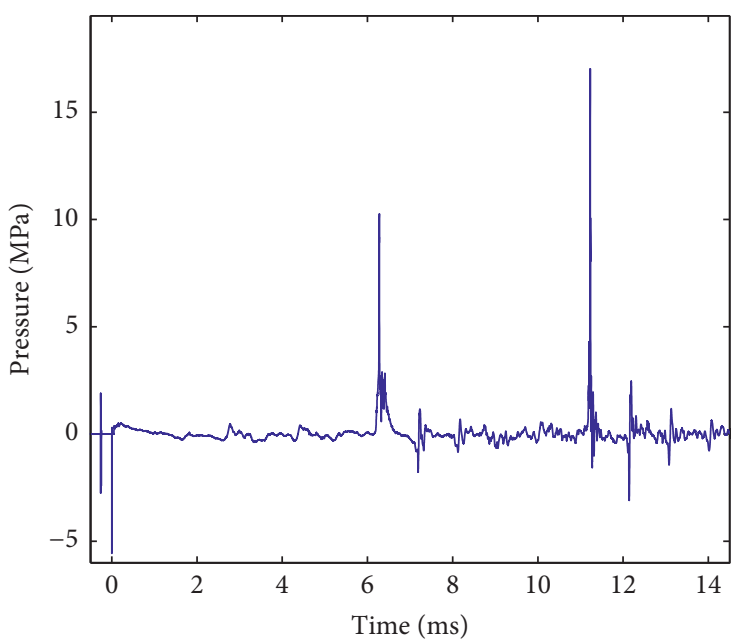

(b)

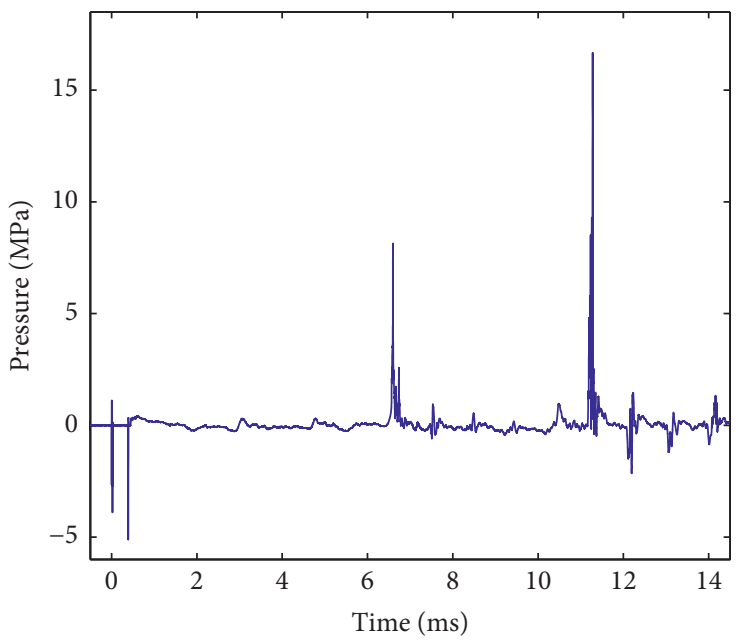

(d)

FIgURE 15: Continued. 


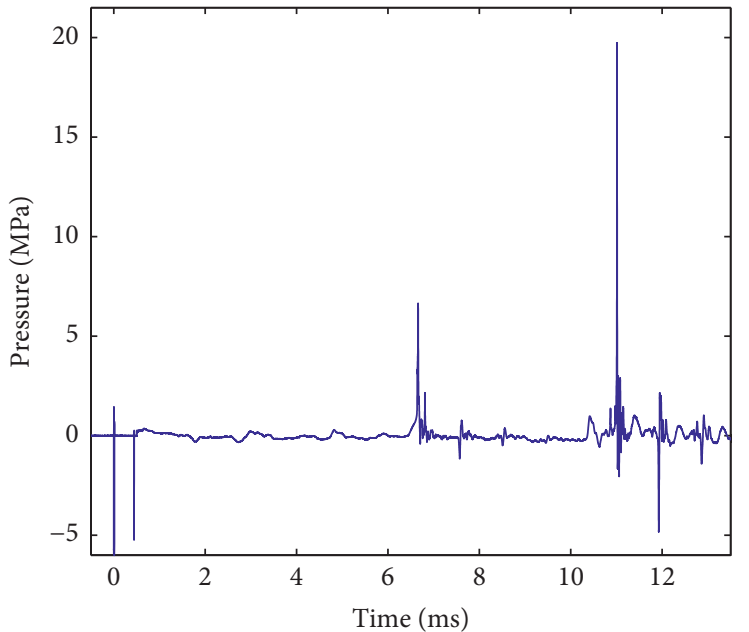

(e)

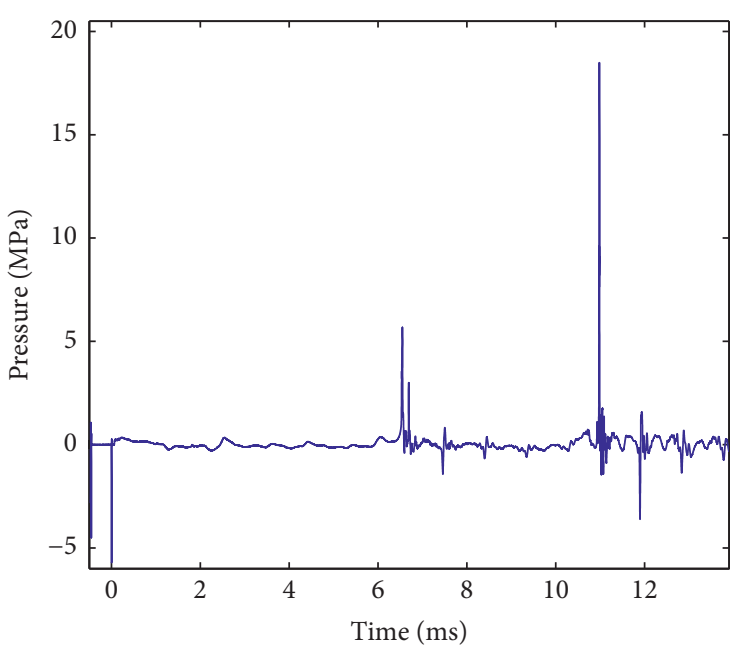

(f)

Figure 15: Pressure-time profile recorded by HPB with a (a) $35 \mathrm{~mm}$, (b) $40 \mathrm{~mm}$, (c) $45 \mathrm{~mm}$, (d) $50 \mathrm{~mm}$, (e) $55 \mathrm{~mm}$, and (f) $60 \mathrm{~mm}$ standoff.

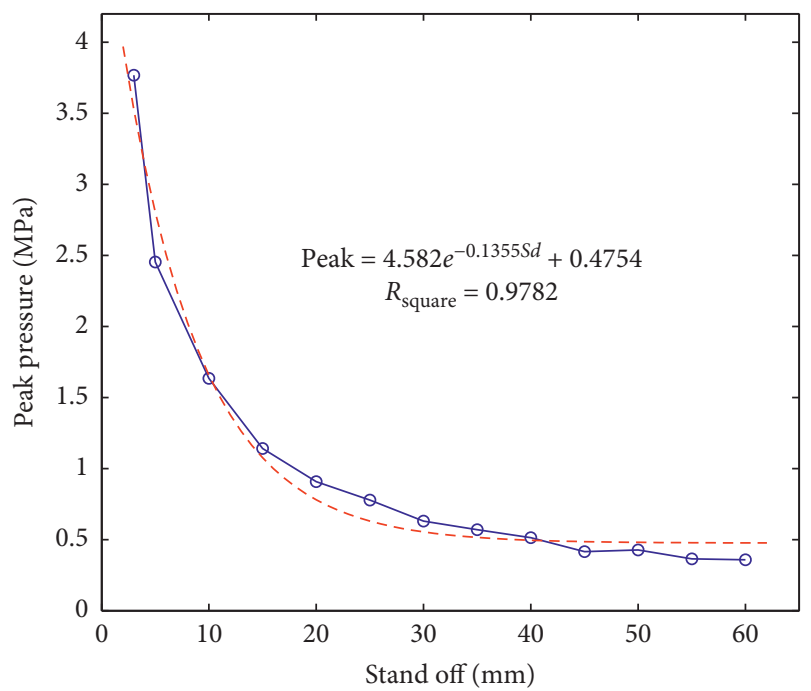

FIGURE 16: Shock wave pressure loading's peak versus standoff.

\section{Conclusions}

In this paper, a Hopkinson pressure bar-based pressure measurement methodology proposed by the current authors is used to assess and study the wall pressure loading due to the underwater spark-generated bubble, which is generated by a discharge of $400 \mathrm{~V} \cdot 400 \mu \mathrm{F}$. In the measurement methodology, the Hopkinson pressure bar, inserted through the hole on the target plate, serves as the sensing element to detect and record the pressure loading. A pair of ropes and a hard rubber cylinder are added to ensure the Hopkinson pressure bar's end face flush with the target plate surface during the whole procedure of the underwater bubble. To validate the assess methodology and to study the relationship between the wall pressure loading and the evolution or the dynamics of the underwater bubble, a high-speed video camera is adopted to capture the images of the underwater bubble. Necessarily, the camera and the data acquisition unit are triggered synchronously.

The shock wave pressure loading generated by the sparkgenerated bubble does not rise directly to its peak but induces multipeak oscillation near the peak. As the standoff rises, the pressure peak decreases as an exponential equation Peak $=4.582 e^{-0.1355 S_{\mathrm{d}}}+0.4754$ with $R_{\text {square }}=0.9782$.

When the standoff is short enough, there is no water jet induced in the bubble shrink procedure, meaning there is only a bubble-collapse loading. As the standoff increases, a water jet is induced. From the results obtained in this paper, when the standoff is shorter than $30 \mathrm{~mm}$, i.e., $\gamma<=1$, the water jet impacts the target plate surface directly, leaving a water jet pressure loading. When the bubble collapses, a bubble-collapse pressure loading with an extremely short duration and a high peak is added. However, it should be pointed out that the induced water jet makes the bubblecollapse procedure smooth when the standoff gets near the maximum radius of the bubble in the free field, resulting in the collapse pressure loading's duration longer and peak lower. With the standoff farther than $30 \mathrm{~mm}$, i.e., $\gamma>1$, there is a gap between the bubble and the target plate surface when the bubble collapses. The water jet does not impact the target as well. So only a bubble-collapse pressure loading acts on the target plate surface. And the collapse loading decreases as the standoff increases.

Especially, another important point should be pointed out in this paper. According to our experiments' results, after the first collapse, the bubble will gather beneath the target plate surface and begin its secondary procedure of expanding and shrinking when the dimensionless distance $\gamma>1$. The rebounded bubble gets in direct contact with the target plate surface. A relatively high collapse pressure loading acts on the target plate. Especially, the secondary bubble-collapse pressure loading is much higher than the first bubble-collapse pressure loading. Even surviving after the first bubble collapse, the structures may be damaged 
under that attack of the secondary bubble collapse, especially for the structures of brittle materials. So enough attention should be paid to not only the first bubble collapse but also the secondary bubble collapse in case $\gamma>1$.

Besides, the HPB used in the experimental system is so long that the application of the system may be limited. The reason why we use such a long HPB is to avoid the mixture of the original and reflected signals. To make the application of the methodology and the experimental system wilder and more flexible, the length of the HPB should be reduced, which means the original signal should be separated from the mixture of the original and reflected signals through the methods given by Zhao and Gary [36] and Bacon [37]. This is an important work which is being done.

\section{Data Availability}

The data used to support the findings of this study are available from the corresponding author upon request.

\section{Conflicts of Interest}

The authors declare that they have no conflicts of interest.

\section{Acknowledgments}

The authors would like to acknowledge the support of the Fundamental Research Funds for the Central Universities (HEUCFP201744) and the National Nature Science Foundation of China (51779056).

\section{References}

[1] P. Cui, A.-M. Zhang, S. Wang, and B. C. Khoo, "Ice breaking by a collapsing bubble," Journal of Fluid Mechanics, vol. 841, pp. 287-309, 2018.

[2] N. D. Taylor, G. Fridman, A. Fridman, and D. Dobrynin, "Non-equilibrium microsecond pulsed spark discharge in liquid as a source of pressure waves," International Journal of Heat and Mass Transfer, vol. 126, pp. 1104-1110, 2018.

[3] B. H. T. Goh, S. W. Gong, S.-W. Ohl, and B. C. Khoo, "Sparkgenerated bubble near an elastic sphere," International Journal of Multiphase Flow, vol. 90, pp. 156-166, 2017.

[4] S. Li, A. M. Zhang, R. Han, and Y. Q. Liu, "Experimental and numerical study on bubble-sphere interaction near a rigid wall," Physics of Fluids, vol. 29, no. 9, article 092102, 2017.

[5] K. Ishii and N. Watanabe, "Shock wave generation by collapse of an explosive bubble in water," Proceedings of the Combustion Institute, vol. 37, no. 3, pp. 3653-3660, 2019.

[6] S. Zhang, A. M. Zhang, S. P. Wang, and J. Cui, "Dynamic characteristics of large scale spark bubbles close to different boundaries," Physics of Fluids, vol. 29, no. 9, article 092107, 2017.

[7] A. M. Zhang, P. Cui, and Y. Wang, "Experiments on bubble dynamics between a free surface and a rigid wall," Experiments in Fluids, vol. 54, no. 10, p. 1602, 2013.

[8] S. W. Gong, S. W. Ohl, E. Klaseboer, and B. C. Khoo, "Interaction of a spark-generated bubble with a two-layered composite beam," Journal of Fluids and Structures, vol. 76, pp. 336-348, 2018.

[9] S. Li, Y.-B. Li, and A.-M. Zhang, "Numerical analysis of the bubble jet impact on a rigid wall," Applied Ocean Research, vol. 50, pp. 227-236, 2015.
[10] Y. L. Liu, Q. X. Wang, S. P. Wang, and A. M. Zhang, "The motion of a 3D toroidal bubble and its interaction with a free surface near an inclined boundary," Physics of Fluids, vol. 28, no. 12, article 122101, 2016.

[11] A. M. Zhang, S. Li, and J. Cui, "Study on splitting of a toroidal bubble near a rigid boundary," Physics of Fluids, vol. 27, no. 6, article 062102, 2015.

[12] Y. Chen, X. Yao, and X. Cui, “A numerical and experimental study of wall pressure caused by an underwater explosion bubble," Mathematical Problems in Engineering, vol. 2018, Article ID 6139510, 10 pages, 2018.

[13] S. Li, R. Han, A. M. Zhang, and Q. X. Wang, "Analysis of pressure field generated by a collapsing bubble," Ocean Engineering, vol. 117, pp. 22-38, 2016.

[14] S. Li, A. M. Zhang, and X. L. Yao, "Experimental and numerical study on the dynamic pressure caused by the bubble jet," Journal of Physics: Conference Series, vol. 656, no. 1, article 012025, 2015.

[15] L. T. Liu, X. L. Yao, A. M. Zhang, and B. S. Sun, "Research on the estimate formulas for underwater explosion bubble jet parameters," Ocean Engineering, vol. 164, pp. 563-576, 2018.

[16] Z. F. Zhang, C. Wang, L. K. Wang, A. M. Zhang, and V. V. Silberschmidt, "Underwater explosion of cylindrical charge near plates: analysis of pressure characteristics and cavitation effects," International Journal of Impact Engineering, vol. 121, pp. 91-105, 2018.

[17] L.-K. Wang, Z.-F. Zhang, and S.-P. Wang, "Pressure characteristics of bubble collapse near a rigid wall in compressible fluid," Applied Ocean Research, vol. 59, pp. 183-192, 2016.

[18] J. R. Krieger and G. L. Chahine, "Acoustic signals of underwater explosions near surfaces," Journal of the Acoustical Society of America, vol. 118, no. 5, pp. 2961-2974, 2005.

[19] A. Jayaprakash, C.-T. Hsiao, and G. Chahine, "Numerical and experimental study of the interaction of a spark-generated bubble and a vertical wall," Journal of Fluids Engineering, vol. 134, no. 3, article 031301, 2012.

[20] J. Luo, W. Xu, J. Deng, Y. Zhai, and Q. Zhang, "Experimental study on the impact characteristics of cavitation bubble collapse on a wall," Water, vol. 10, no. 9, p. 1262, 2018.

[21] X. Cui, X. Yao, and Y. Chen, "A lab-scale experiment approach to the measurement of wall pressure from near-field under water explosions by a Hopkinson bar," Shock and Vibration, vol. 2018, Article ID 8273469, 15 pages, 2018.

[22] X. Yao, K. Guo, Y. Chen, and X. Cui, "A new experimental methodology to assess the wall pressure generated by a highvoltage underwater spark-generated bubble," Results in Physics, vol. 12, pp. 571-574, 2019.

[23] B. Hopkinson, "A method of measuring the pressure produced in the detonation of high explosives or by the impact of bullets," Philosophical Transactions of the Royal Society A: Mathematical, Physical and Engineering Sciences, vol. 213, no. 497-508, pp. 437-456, 1914.

[24] H. Kolsky, "An investigation of the mechanical properties of materials at very high rates of loading," Proceedings of the Physical Society. Section B, vol. 62, no. 11, pp. 676-700, 1949.

[25] S. E. Rigby, A. Tyas, S. D. Clarke et al., "Observations from preliminary experiments on spatial and temporal pressure measurements from near-field free air explosions," International Journal of Protective Structures, vol. 6, no. 2, pp. 175-190, 2015.

[26] S. D. Clarke, S. D. Fay, J. A. Warren, A. Tyas, S. E. Rigby, and I. Elgy, "A large scale experimental approach to the measurement of spatially and temporally localised loading from 
the detonation of shallow-buried explosives," Measurement Science and Technology, vol. 26, no. 1, article 015001, 2015.

[27] S. D. Clarke, S. D. Fay, J. A. Warren et al., "Predicting the role of geotechnical parameters on the output from shallow buried explosives," International Journal of Impact Engineering, vol. 102, pp. 117-128, 2017.

[28] S. E. Rigby, S. D. Fay, A. Tyas et al., "Influence of particle size distribution on the blast pressure profile from explosives buried in saturated soils," Shock Waves, vol. 28, no. 3, pp. 613-626, 2018.

[29] S. E. Rigby, S. D. Fay, S. D. Clarke et al., "Measuring spatial pressure distribution from explosives buried in dry Leighton Buzzard sand," International Journal of Impact Engineering, vol. 96, pp. 89-104, 2016.

[30] T. J. Cloete and G. N. Nurick, "Blast characterization using a ballistic pendulum with a centrally mounted Hopkinson bar," International Journal of Protective Structures, vol. 7, no. 3, pp. 367-388, 2016.

[31] S. Park, T. Uth, N. A. Fleck, H. N. G. Wadley, and V. S. Deshpande, "Sand column impact onto a Kolsky pressure bar," International Journal of Impact Engineering, vol. 62 , pp. 229-242, 2013

[32] R. Han, A. Zhang, and Y. Liu, "Numerical investigation on the dynamics of two bubbles," Ocean Engineering, vol. 110, pp. 325-338, 2015.

[33] X. Ma, B. Huang, X. Zhao et al., "Comparisons of sparkcharge bubble dynamics near the elastic and rigid boundaries," Ultrasonics Sonochemistry, vol. 43, pp. 80-90, 2018.

[34] R. P. Tong, W. P. Schiffers, S. J. Shaw, J. R. Blake, and D. C. Emmony, "The role of 'splashing' in the collapse of a laser-generated cavity near a rigid boundary," Journal of Fluid Mechanics, vol. 380, pp. 339-361, 1999.

[35] T. Li, S. Wang, S. Li, and A.-M. Zhang, "Numerical investigation of an underwater explosion bubble based on FVM and VOF," Applied Ocean Research, vol. 74, pp. 49-58, 2018.

[36] H. Zhao and G. Gary, "A new method for the separation of waves. application to the shpb technique for an unlimited duration of measurement," Journal of the Mechanics and Physics of Solids, vol. 45, no. 7, pp. 1185-1202, 1997.

[37] C. Bacon, "Separation of waves propagating in an elastic or viscoelastic hopkinson pressure bar with three-dimensional effects," International Journal of Impact Engineering, vol. 22, no. 1, pp. 55-69, 1999. 


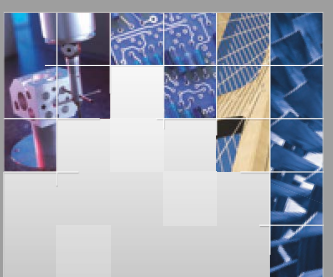

\section{Enfincering}
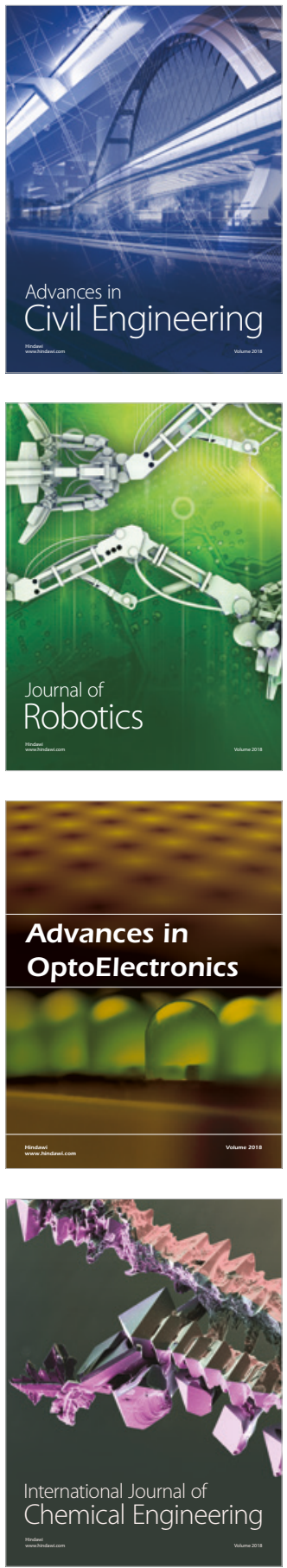

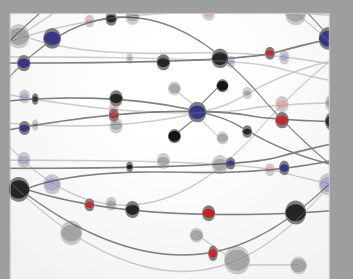

\section{Rotating \\ Machinery}

The Scientific World Journal

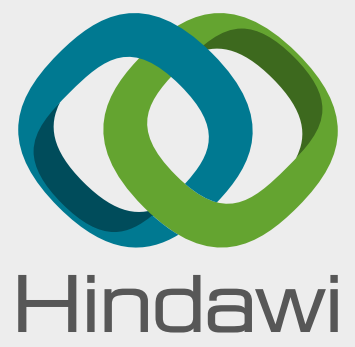

Submit your manuscripts at

www.hindawi.com
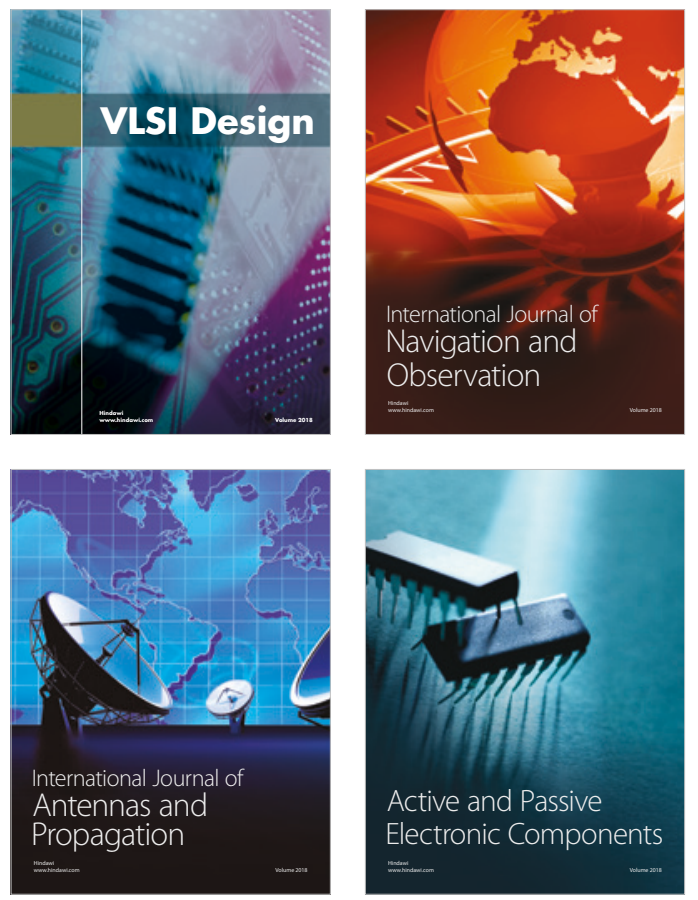
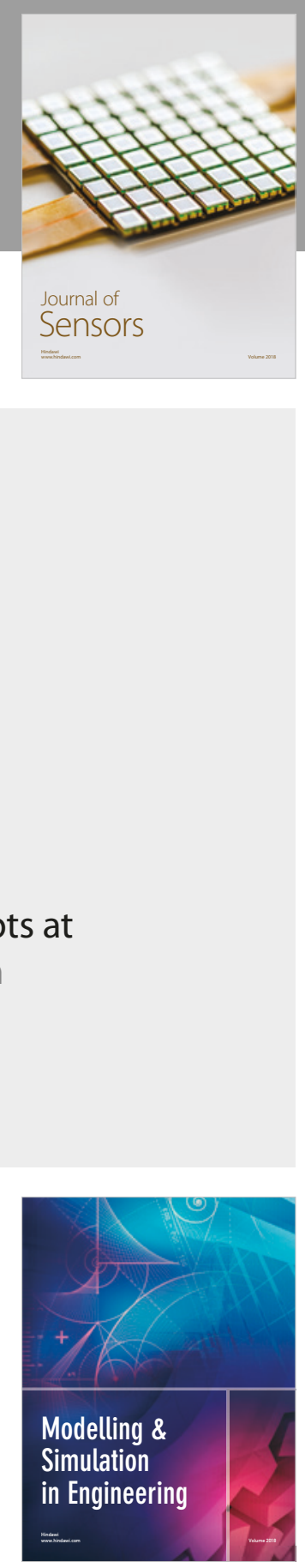

\section{Advances \\ Multimedia}
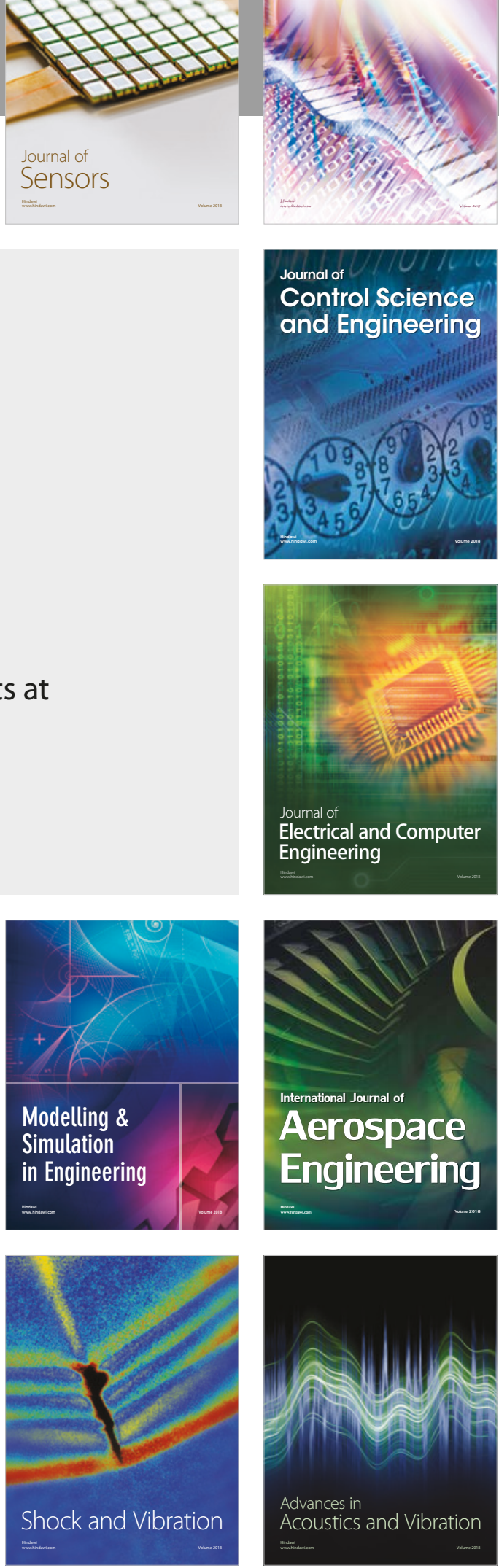